Review Article

\title{
The Burden of Visceral Leishmaniasis in India: Challenges in Using Remote Sensing and GIS to Understand and Control
}

\author{
Gouri Sankar Bhunia, ${ }^{1}$ Shreekant Kesari, ${ }^{1}$ Nandini Chatterjee, ${ }^{2}$ \\ Vijay Kumar, ${ }^{1}$ and Pradeep Das ${ }^{1}$ \\ ${ }^{1}$ Department of Vector Biology and Control, Rajendra Memorial Research Institute of Medical Sciences (ICMR), Agamkuan, \\ Bihar, Patna 800 007, India \\ ${ }^{2}$ Department of Geography, Presidency University, 86/1, College Street, West Bengal, Kolkata 700 073, India
}

Correspondence should be addressed to Pradeep Das; drpradeep.das@gmail.com

Received 3 July 2012; Accepted 14 August 2012

Academic Editors: E. Çiftçi, K. Couper, and M. A. De Souza

Copyright (C) 2013 Gouri Sankar Bhunia et al. This is an open access article distributed under the Creative Commons Attribution License, which permits unrestricted use, distribution, and reproduction in any medium, provided the original work is properly cited.

\begin{abstract}
Visceral leishmaniasis (VL) continues to constitute immense public health problems and be an obstacle to socioeconomic development in India. The scrutiny of this disease remains a necessary step in its control, eradication, and prevention. Space technologies proffer new opportunities for rapid appraisal of endemic areas, stipulation of trustworthy estimation of populations at risk, prediction of disease distributions in areas that lack baseline data and are difficult to access, and guiding intervention strategies. Here, we focus on the epidemiology and control of VL in India and review remote sensing (RS) and GIS applications to date. For the original evidenced report, a search was done on electronic databases of PubMed, ERMSS, EQUEST and from online Internet searching to come across the recent research problems. We discuss the previous work conducted in this field, outlined potential new applications of GIS and RS techniques, and utilization of emerging satellite information, as they hold a promising area to further enhance VL risk mapping and prediction. Finally, we concluded with a discussion of strategies to overcome some of the perspective challenges of GIS and RS applications for VL control, so that supplementary and continued progress can be made to control this disease in India and elsewhere.
\end{abstract}

\section{Introduction}

Visceral leishmaniasis (VL), a vector-borne disease, has been endemic in India since ancient times [1,2]. At present, it is a serious public health problem in Indian subcontinent, especially in Bihar state. Leishmania donovani parasites are the causal agents of visceral leishmaniasis, a group of protozoan disease transmitted to humans by the female phlebotomine sand fly (Phlebotomus argentipes). VL, locally known as kala-azar in India, predominantly targets the poorest of the poor and affects the internal organs principally spleen, liver, and bone marrow. Internationally, the disease is endemic in 88 countries, infecting around two million people each year $[3,4]$. It is mostly endemic in countries that are among the least developed in the world. India, Nepal, and Bangladesh harbor an estimated $67 \%$ of the global VL disease burden [5].
There have been numerous outbreaks of kala-azar in India, since last century [1]. Conversely, information on epidemiology of kala-azar in India still remains scanty. Nevertheless, the information on kala-azar epidemiology will be valuable to comprehend the current status of the disease [6]. In India, the disease attacks young children and older adults [7]. Various programmes to control the disease have failed despite substantial work being done on assorted aspects of the disease. Government-led efforts to control VL in India have been exemplary [8-10]. However, in some areas, the control of VL proved particularly challenging that is, lower and Middle Gangetic Plain. It is estimated that more than 90\% VL-infected people in India are concentrated in this region. In recent years endemic regions extended, prevalence increased, and even an outbreak of the disease took place [11]. However, there was no national VL 
case reporting system or surveillance system before 2005 in India, VL case records and statistics were not existing, and the information on exact number of cases, geographic distributions, and so forth was not noticeable. From 2005, VL cases were reported compulsorily in India according to the National Vector Borne Disease Control Program (NVBDCP).

It is widely accredited that the frequency as well as transmission dynamics of VL is closely interrelated to socioeconomic, climatic, and environmental factors, the latter including land use/land cover, topography, rainfall, temperature, and vegetation coverage [12-16]. The advent of geographic information systems (GISs) and remote sensing (RS) technologies opened new avenues to evaluate digital map data generated by earth observing satellite sensors for spatial and temporal environment analyses [17-21]. This facilitates prediction of leishmaniasis transmission and in turn provides direction to local authorities in decisionmaking and policy planning for cost-effective resource allocation [22-24]. In India, the application of GIS and RS technologies to VL dates back to the late 2000s and early 2006s. Particular emphases have been placed on mapping prevalence, association of Phlebotomus argentipes habitats, and forecasting transmission risk in relation to ecological transformation.

The purpose of this paper is to review the various applications of GIS and RS, and to discuss their contributions in further understanding the epidemiology and control of VL in India. Subsequently, we review applications of GIS and RS for identification and prediction of risk areas due to the presence of $P$. argentipes. Finally, we confer current research needs and conclude that further progress in GIS and RS holds promise to conquer some of the perspective challenges in the control of VL in India, which is likely to have broad applicability to other VL-endemic areas of the world.

\section{Methods}

The present study was a retrospective review of VL cases notified between 1987 and 2011 based on the passive surveillance data reported through the Directorate General of Health Services and National Vector Borne Disease Control Programme (NVBDCP), Government of India. All reported VL cases were diagnosed in accordance with the passive case detection method for VL diagnosis in India and reported via NGO and public health centers (PHCs). In this study, data were tabulated, diagrammatized, and investigated through descriptive statistics in a Microsoft Excel spreadsheet, release 2007. We searched for peer-reviewed literature using several bibliographic databases (e.g., PubMed, ERMSS, and EQUEST), and search for definitions of "remote sensing and GIS" and "VL" was restricted to English language. Additionally, investigations were also carried out of leading public health journals and identified key papers from the reference lists of the journal articles. Also, literatures related to our subject presented in various congresses and meetings in recent decades were reviewed.

\section{Results}

3.1. Kala-Azar Situation in India. From 1987 through 2011, a total of 7, 60, 432 kala-azar cases were reported in India; the data were collected by the National Institute of Communicable Disease (NICD), Directorate General of Health Services, and National Vector Borne Disease Control Programme (NVBDCP), Government of India. Nevertheless, the data have broad coverage and are useful to examine geographic distribution and trends over time. Annual kala-azar case totals ranged from 12,140 in 2002 to 77,102 in 1992, with a mean of reported per year of 30417.28. The trend of rising incidence was found in 1990-1993 and 2005-2008 (Figure 1).

Kala-azar cases were reported from 52 districts (e.g., 4 main states) of India. However, Bihar (31 districts), West Bengal (6 districts), Jharkhand (4 districts), and Uttar Pradesh (11 districts) were highly affected states by this disease (Figure 2). Furthermore, more than $70-80 \%$ kala-azar cases were reported from Bihar only. In 2010, 79.76\% positive cases were contributed by Bihar only; whereas $14.87 \%$ in Jharkhand, $5.12 \%$ in West Bengal, and $0.04 \%$ in Uttar Pradesh, as a proportion of a country. Ten districts of the state (Muzaffarpur, Purnea, Saharsa, Ararea, Vaishali, Madhepura, East Champaran, Samastipur, Saran, and Darbhanga) have been reporting more than $75 \%$ of the total cases for several years (source: report from the State Health Society, Bihar, India). However, most of these districts are located north of the river Ganges, and a spot map shows almost in similar distribution.

From 1987 through 2011, a total of 6,70,897 kala-azar cases were reported officially from Bihar only (Figure 3); the data were collected by the National Institute of Communicable Disease (NICD) and Directorate General of Health Services, Government of India at the block level (public health centres). Nevertheless, the data have broad coverage and are useful to examine geographic distribution and trends over time. Annual incidence of kala-azar cases was ranged from 1.14 to 8.76 per 10,000 populations, with an average incidence rate of 3.05 (standard deviation \pm 0.38 ). The highest incidence was recorded in 1992 (8.76/10,000 population). The disease has appeared in epidemic form in the years 1992 and 2007 causing high morbidity and mortality (Figure 3). The trend is more visible showing declining trend after 1993 to 1995 , increasing trend after 1995 till 1996, decreasing trend after 1997 till 2004, and again increasing trend after 2005 till 2008, yet again turning down in 2009. The maximum intensity of disease was found during the period from 1990 to 1993.

There are several major outbreaks of kala-azar experienced by West Bengal State before 1950 [6]. During 1987-2011, approximately 47,894 cases of kala-azar were recorded from West Bengal. The incidence over the period showed two peaks in 1987 and 2004, respectively, and a small peak was found in 1996. The epidemic trend is more visible, showing declining trend after 1987 till 1994, slightly increased trend after 1995 till 1996, and decreasing trend after 1997 till 2003; again increasing trend 2004 till 2007, decreasing trend in 2009, and again increasing in 2011 onwards. However, in 1990, new resurgence of epidemic foci of kala-azar was found in Darjeeling district. In West Bengal, highest numbers 


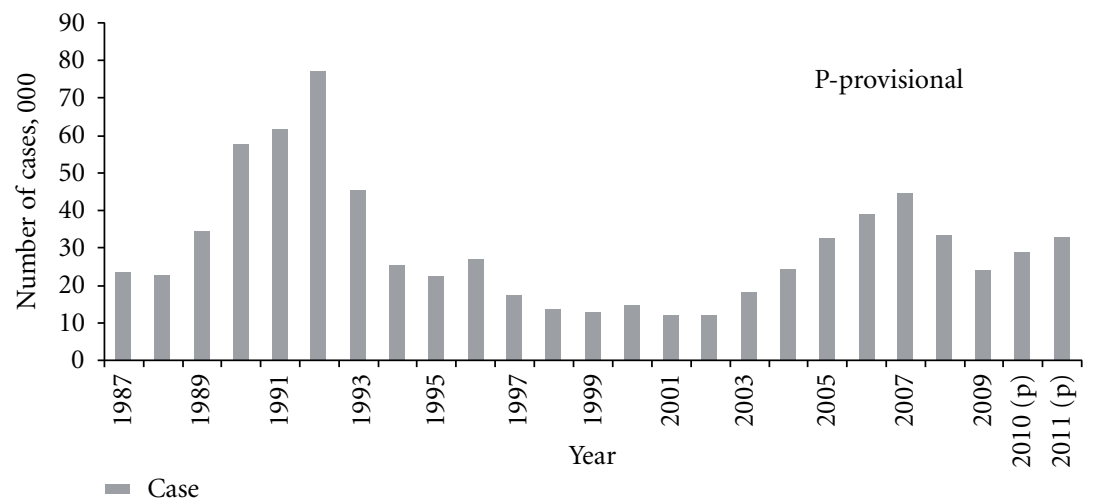

Figure 1: Kala-azar cases in India during the period from 1987 to 2011 (source: Directorate General of Health Services, National Vector Borne Disease Control Programme (NVBDCP), Government of India, and State Health Society, Bihar, India).

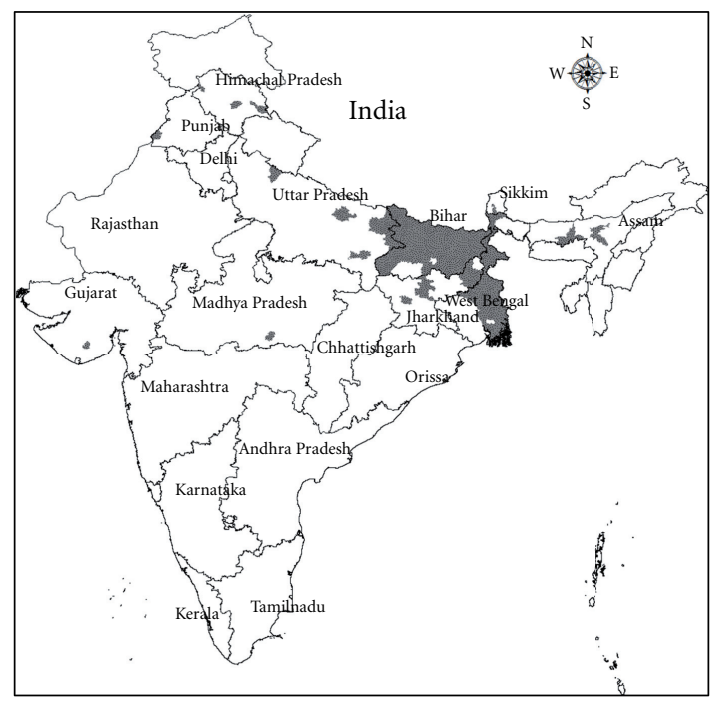

State boundary

VL-affected regions in India

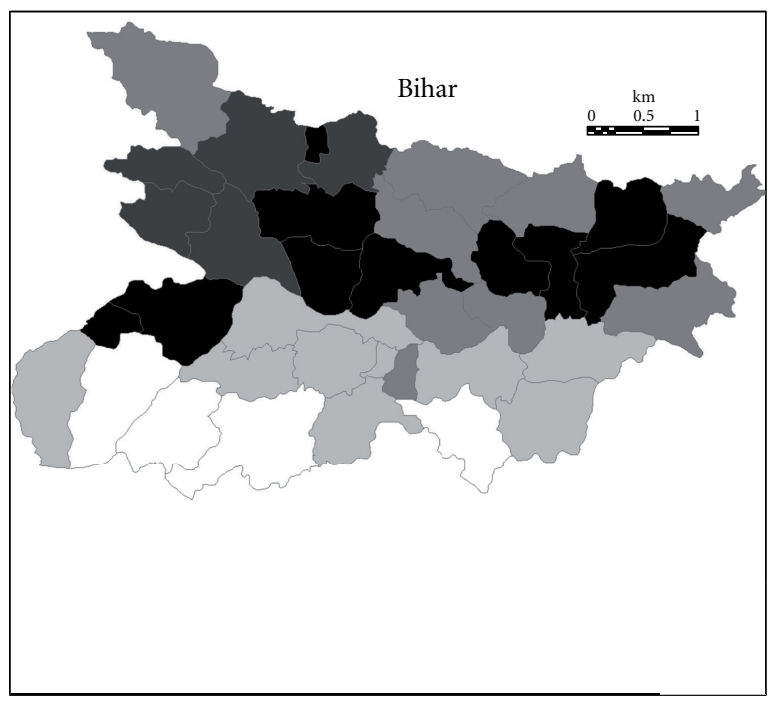

Cumulative VL incidences per 10000 population

(during the period of 2007-2011)

$\begin{array}{lll}\text { No VL cases } & 15.01-25 \\ <5 & \square 25.01\end{array}$

(b)

(a)

FIgURE 2: (a) Geographical distribution of visceral leishmaniasis (VL) in India including reported sporadic cases during the period from 2007 to 2011 (source: National Vector Borne Disease Control Programme (NVBDCP), 22 Shamnath Marg, Delhi, available at http://www.nvbdcp.gov.in/ka-cd.html); (b) geographical distribution of VL in Bihar. The figure shows the cumulative incidence rate per 10,000 population during the period from 2007 to 2011 (source: State Health Society, Bihar, India).

of cases were recorded from the Malda and Murshidabad districts during the study period. The least affected districts were Nadia and Hooghly. Moreover, the Jharkhand state accounted for 44,180 reported cases during the period from 2000 to 2011. Highest number of cases recorded during 2006 (7,508 cases), followed by sharp declining till 2009, and again increasing in trend till 2011.
3.2. Research on Visceral Leishmaniasis Using Remote Sensing and GIS in India. Table 1 recapitulates the different studies that applied GIS and RS technologies for infection risk mapping and transmission modeling of VL in India. For each study, its aim, area, method and scale of application, and key environmental, demographic and/or epidemiological parameters are given. The majority of these studies 


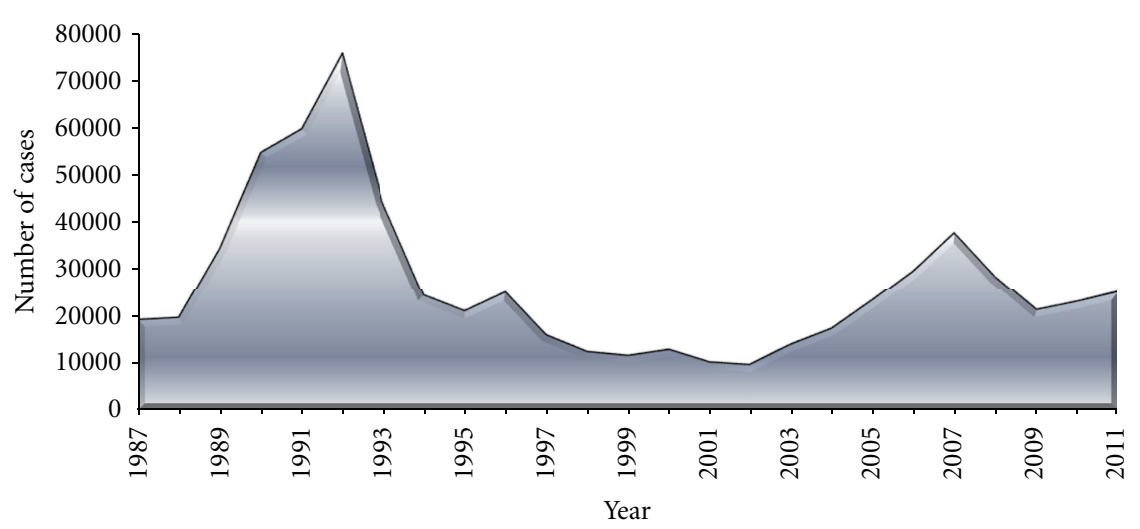

Figure 3: Kala-azar cases in Bihar during the period from 1987 to 2011 (source: Directorate General of Health Services, National Vector Borne Disease Control Programme (NVBDCP), Government of India, and State Health Society, Bihar, India).

focused on the meso (district) and/or macro (national) level.

Data used is one of the major limitations of using RS, and inventive ways of acquiring data are critical to accomplishment of space technology. Much of this literature deals with remote sensing in the form of medium and high resolution satellite imagery. The goal of these studies is to see if any relationships exist between disease incidence/prevalence and environmental variables, like regional climate (temperature, relative humidity, rainfall, etc.) land use/land cover, inland surface water bodies, elevation, and soil. Low spatial resolution satellite data have been used extensively for regional and continental distribution studies. In most of the cases these studies involve testing to see correlation between satellites derived environmental proxies with the changes in $P$. argentipes abundance and distribution. An innovative application of RS and GIS was described by Bhunia et al. [14] that analysed the usefulness of satellite data for monitoring and mapping the distribution and incidence of VL on the Gangetic Plain, and to identify the main environmental parameters that affect the disease in this region. The results of this study signified some clear-cut links-such as those between endemic VL and fluvisols and certain ranges for some climatic variables (e.g., mean annual values, for temperature, relative humidity, and precipitation, of $25.0-27.5^{\circ} \mathrm{C}$, $66 \%-75 \%$, and $100-160 \mathrm{~cm}$, resp.) - that should be useful in the rapid identification of areas at high risk for VL in India. Another successful application of RS was to make the association between topography and VL distribution [13]. This work confirmed that the highest prevalence of VL was below $150 \mathrm{~m}$ of altitude with very few cases located above the $300 \mathrm{~m}$ mean sea level in India.

In Bihar, India, a study on potential $P$. argentipes habitat was performed by a spatial analysis of RS data [25]. Malaviya et al. [26] scrutinized the spatial distribution of reported cases of VL in the 4 study periods from 1990 to 2008 in Muzaffarpur district, Bihar, India. The analysis revealed that some blocks had constantly higher (Sahebganj and Bochahan block) or lower (Sakra block) standardize incidence ratio (SIR) over time. They also observed that the western blocks of the district (Muzaffarpur, Bihar, India) registered the higher number of cases every month and no big shifts (i.e., blocks going from very low to very high SIR). Investigation suggested an association with inland water bodies of areas that poses a risk for VL by offering suitable breeding sites for $P$. argentipes. More recently, Bhunia et al. [27] made significant contribution by delimitating the probable endemic areas for kala-azar based on geoenvironmental risk model. From the satellite image taken during the dry season NDVI, tasseled cap transformation and land use/land cover were extracted and were used in the geoenvironmental risk model. Model parameters were grouped in different risk classes by calculating the risk indices based on their score on the model. Finally, it is important to note that a research group built around a joint research interchange programme between Rajendra Memorial Research Institute of Medical Sciences (Indian Council of Medical Research) and Regional Remote Sensing Centre-East (National Remote Sensing Agency) made significant contributions to the application of RS and GIS for better understanding the sand fly abundance of the endemicity of kala-azar in an endemic focus of India [28]. Studies carried out by Bhunia et al. [12] used some geostatistical measurements of spatial distribution of disease to analyze the locational information. In this study, it was shown that plotting standard deviation of ellipse for disease outbreak overtime may be used to model disease spread and mapping the distributional trend.

3.3. RS and GIS for Identification of Vector Habitat of $V L$ in India. The frequency and transmission dynamics of VL is intimately linked with the distribution Phlebotomus argentipes, which in turn is a result of the distribution and abundance of suitable sand fly habitat that consists of a suitable environment. Table 2 recapitulates the studies published to date with an emphasis on identifying suitable habitat through appropriate amalgamation of RS and GIS technologies. However, the majority of the studies focused on the meso scale. Sudhakar et al. [16] first used RS techniques to identify $P$. argentipes habitats in an endemic (Vaishali district) and nonendemic (Lohardaga district) areas of kalaazar. Employing satellite images, the study area was classified 


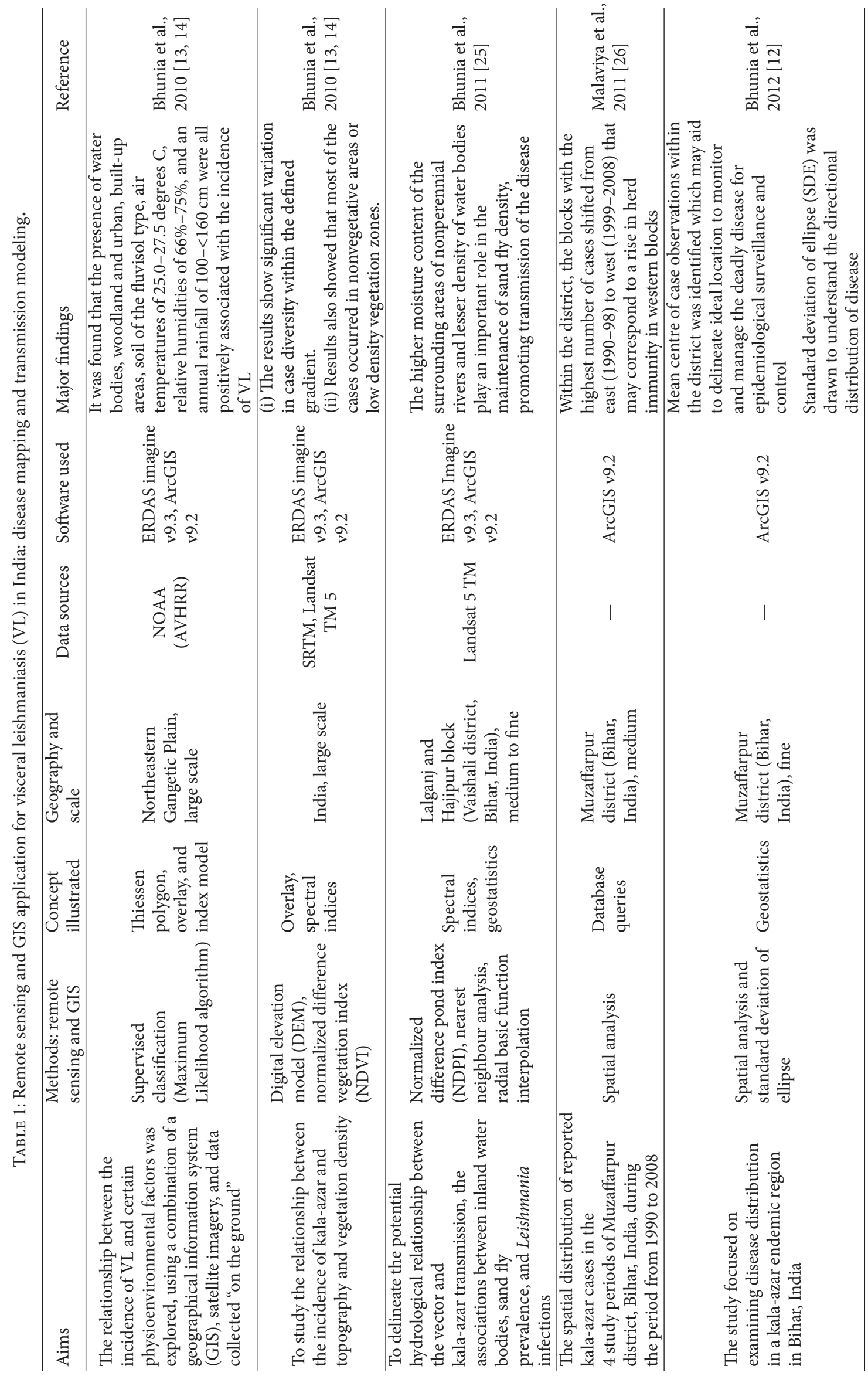




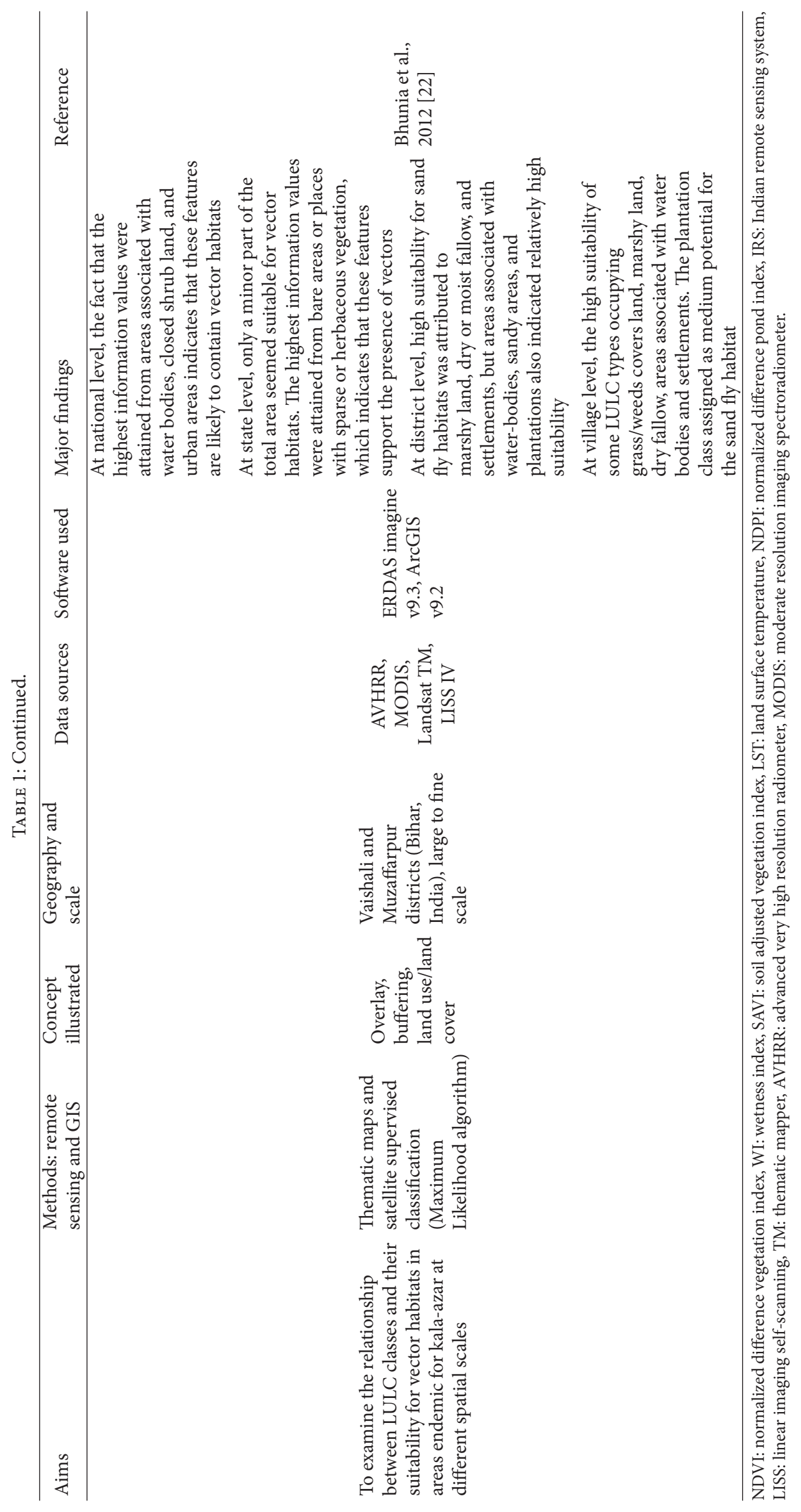




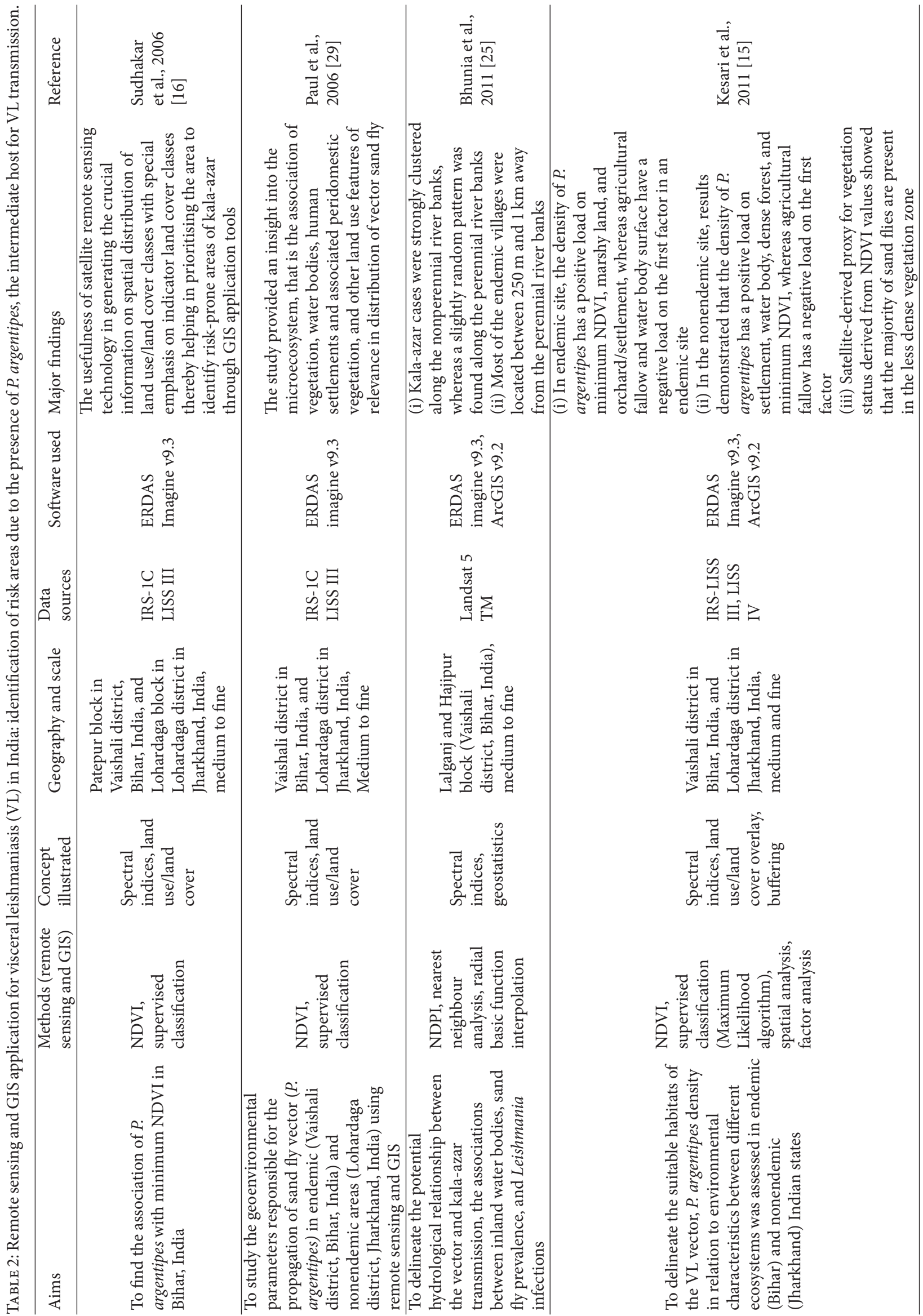




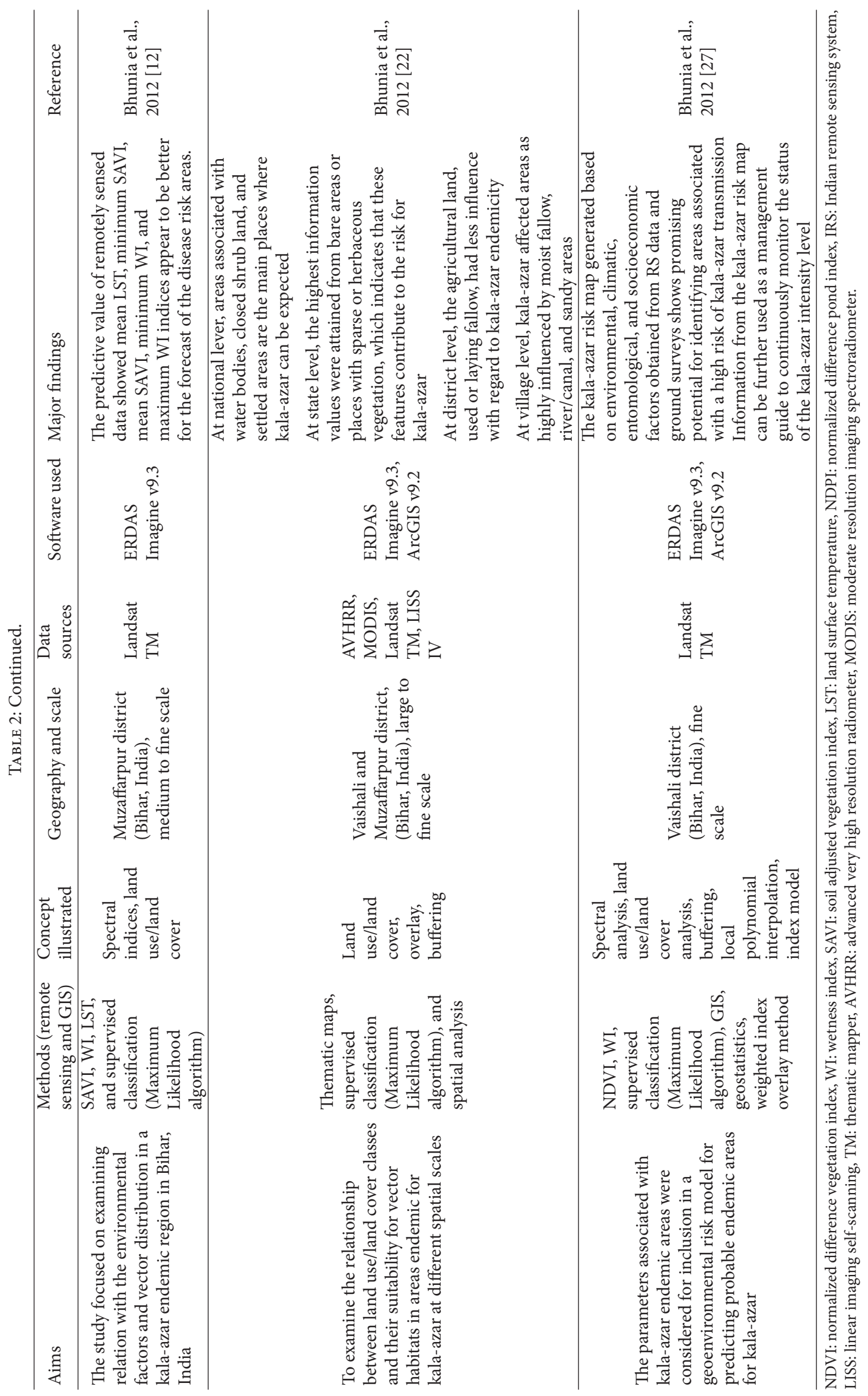


into several ecological zones based on land use/land cover characteristics and vegetation coverage. It was found that vegetation, water bodies, and settlements played a great role on sand fly abundance and distribution in the study area. Paul et al. [29] used Indian remote sensing satellite (IRS) linear imaging self-scanning (LISS)-III satellite sensor data to identify geoenvironmental parameters responsible for the propagation of sand fly vector (P. argentipes). In their study, it was observed that satellite derived NDVI, land use and soil moisture, temperature, humidity data have very good correlation with man-hour density of sand fly. Kesari et al. [15] studied suitable habitats of the VL vector, $P$. argentipes density in relation to environmental characteristics between different ecosystems, performed an IRS P6 LISS IV satellite imagery, using factor analysis. They observed that the density of $P$. argentipes has a positive load on minimum NDVI, marshy land, and orchard/settlement, whereas agricultural fallow and water body surface have a negative load on the first factor in an endemic site. In another study, Bhunia et al. [22] carried out to scrutinize the relationship between LULC classes and their suitability for vector habitats in areas endemic for kala-azar at different spatial scales. The connotation of this approach laid in its success in predicting the overall distribution of areas suitable for the vectors, which is due to the different sensor resolutions (national, state, district, and village level) and the fact that a thorough LULC analysis can predict the probability for disease transmission. Bhunia et al. [12] also conducted a research on prediction of $P$. argentipes abundance based on land surface temperature (LST), soil adjusted vegetation index (SAVI), and wetness index (WI). The predictive model indicated that nearly $85 \%$ of the variance of sand fly density could be explained by these variables.

\subsection{Perspective of RS and GIS Challenges to Be Considered in} VL Control. Our literature review showed that few studies have applied GIS and RS technologies, often in combination with spatial statistics, for infection risk mapping and predictive modelling of VL in India. However, there is scope for application of novel GIS/RS techniques, notably quantitative GIS, WebGIS, and innovative use of new satellites information that will become available shortly. However, the application of GIS/RS with the aim to further progress current approaches and strategies would be used for the control of VL in India and in turn might arouse control programmes elsewhere.

3.5. Improved Monitoring and Its Usefulness. RS data are particularly handy in examining changes in broad area or earth system instability, that are especially relevant to disease emergence take in global climate change and land use change. Remote sensing sensor will improve the science of mapping VL risk in subtropical areas, particularly with access to increase spatial and temporal resolution. Analyses resulting from the combination of GIS and RS have improved knowledge of the biodiversity influencing kala-azar. A better understanding of the stratification of kala-azar and the burden of the disease on the population is in progress [3032]. This information can help decision-makers to improve apportion of limited resources in the fight against the disease. It was therefore necessary to improve the predictability of kala-azar by forecasting it with a longer lead time before the outbreak. By adding climatic and environmental factors to the model, the predictive accuracy of the system could have been enhanced.

3.6. Need to Develop Standards. GIS in the future will be a combining concern with standards, including the tribulations of data definition, utility definition, data accuracy, and data exchange. The one stipulation in this regard, however, may be the proclivity for governments to use the explanation of data standards to validate treating spatial data as a commodity, thereby challenging weighty imbursement and preventive usage agreements. For example, governments must define standard formats (e.g., ARC/INFO, Shapefile format) to be followed in GIS to the GIS user groups. Since, several departments of various ministries were already using GIS. These maps would comply with the defined standards and would be available and used by all the ministries concerned. Moreover, this would save the cost and money of base layer preparation by sharing the digitized cartographic database of various departments within the country. This proffers the possibility, if necessary, of exchanging to more powerful softwares and collaborating with research laboratories and institution which may crave to enhancement of the analyses with studies assimilating satellite imagery.

3.7. Facility of Enabling Technology. Spectral and spatial resolution will continue to improve. Compared to submeter spatial resolution and hundreds of bands of hyperspectral data available today, that may aids to choose a dozen of bands carefully to detect environmental effects on kalaazar transmission. On the other hand, satellite-borne radar systems (Radar Imaging Satellite, RISAT) have reduced cloud cover problems and offers ability to investigate the environmental characteristics for epidemiological analysis during the monsoon season. These active systems' articulate energy allows meticulous mapping of elevation differences, even centimeter-scale changes in elevation through time. Data prices have decreased. Perhaps the most spectacular price pitch is for satellite data [33]. A few data sets are still quite expensive, but the overall price trend is downward. Satellite data processing is trending toward more adaptable, powerful, image processing software, and faster straps to GIS. Using high resolution, stereoscopic data, and powerful software packages, one can extract accurate, quantitative information unswervingly from remote sensing data.

3.8. Align Data Policies to Technological Advances. RS data of a country has military and economic value and should not essentially be liberally accessible to everyone. Space is gratis for all, and earth-orbiting satellites maneuvered by a few countries incessantly make meticulous observations of the territory of each country in the planet. Therefore, intercontinental efforts are ongoing to shield the rights of each creature country to have admittance to its data at nondiscriminatory circumstances. This issue falls within the domain 
of what is called "data policy" [34]. The world is witnessing an increasing eagerness for geospatial information and highresolution RS data. But clearly defined policies on remote sensing data acquisition and distribution are inflexible to come by. Due to unavailability of the required data and information products or complementary data, it is difficult to link the epidemiological and entomological data with the GIS system. These results discourage the use of GIS for kalaazar research and control.

Recently, the Government of India consents to the RS data policy (RSDP), having modalities for managing and/or permitting the attainment or propagation of RS data in support of developmental activities. Additionally, the RSDP stated that "for acquisition/distribution of IRS data for use in countries other than India, the Government of India, through the nodal organization, would allowance license to such bodies/agencies of those countries as are interested in the acquisition/distribution of IRS data, as per specific procedures" [35].

3.9. Data Sharing-Inadequate Human Resource. The major problem of GIS users has been faced for decades regarding the data efficacy and sharing. Administrative boundary layer, thematic map, and disease data sharing are vital for the collaborative research, retort, and recovery stages of disease control. For kala-azar studies, it is imperative to employ distributed disease information and allocate the data through standard interfaces. In evaluating disease information and the health decision-making process, it is cooperative to assimilate many kinds of spatial and nonspatial data, including roads, hospitals and available medical resources $[36,37]$. The fact that GIS is a comparatively new technology means that staffs with GIS training and skills are in high demand and beyond attain of most health department budgets. The government should introduce geospatial electives in art, science, and engineering colleges and universities. Pursuing this need to share and integrate information across state and nationwide may reduce the burden of inadequate human resources.

At present, study limitations are often due to low spatial resolution remotely sensed environmental data. However, with the recent launch of new and powerful satellites, it has become possible to make use of higher resolution RS data at relatively low costs and/or freely. For example, the DigitalGlobe QuickBird satellite, a commercial satellite with the utmost freely accessible resolution to date, was fruitfully lifted in the orbit in late 2001. This satellite has $0.61-0.72 \mathrm{~m}$ panchromatic and $2.44-2.88 \mathrm{~m}$ multispectral sensors, depending upon the off-nadir viewing angle $\left(0^{\circ}-25^{\circ}\right)$. QuickBird's basic image products are delivered to cover a single area of $16.5 \times 16.5 \mathrm{~km}$ or a strip of $16.5 \times 165 \mathrm{~km}$. QuickBird's high spatial resolution sensors have narrowed the gap between satellite images and aerial photos. Thus, it is plausible that QuickBird's technology will replace aerial photos for various applications, depending on resolution and accuracy requirements [38].

Indian Space Research Organization (ISRO) Space Application Center (SAC) has just finished that promising by an innovation which is called "Bhuvan." At present, ISRO
Bhuvan has serious concert issues and packs a lot of data on weather, water bodies, and population details of various administrative units. Bhuvan proffers more detailed imagery of Indian locations compared to other Virtual Globe software, with spatial resolutions ranging from 5 to 100 metres. Locations can be analyzed from different viewpoints, and the software will also afford functionality for the measurement of distances (http://www.isrobhuvan.in/). With Bhuvan, it may be possible to produce very local information which will be specific to only to the India in free of cost and timely and least cost effective make a relationship. This information available from this mapping system will be useful in addressing very local problems like seasonal status of vegetation, land use/land cover characteristics, weather condition that will be easy to make an association between environmental variable and disease vis-à-vis sand fly distribution, and environmental modeling.

3.10. Institualization of Innovation. The first step in employing a spatial and space technology in an organization is to generate awareness and support for the methodology among the ultimate recipients and users of the system. The combination of space application centers and medical research centre unites technical skills with the culturalinstitutional knowledge, which imparts contextual acquaintance and methodologies that are both scientific and reflexive. In general perspective aptitude can be expressed as the capability of individuals and institutions to make and execute decisions and achieve functions in an effectual, proficient, and sustainable approach. Enhancement training centers and circular modules within health centres, colleges and universities to assure the availability and preparedness of the next generation of specialists in geospatial information, image analysis, spatiotemporal data product development and decision support for government agencies vested with responsibility for vulnerability assessment.

3.11. Cloud Computing. Cloud computing (CC) is emerging as a key computing platform for allotment resources that include infrastructures, software, applications, and business processes $[39,40]$. CC can be apparent as having five key characteristics (on-demand self-service; ubiquitous network access; location-independent resource pooling; rapid elasticity; pay-per-use), three delivery models (SaaS-software as a service, PaaS-platform as a service, and IaaS-infrastructure as a service), and four deployment models (private, community, public, and hybrid) [41]. In VL control programme, GIS cloud may make available dedicated structure for analyzed, authored, and managed geospatial data through web services and application hosting for the organization. The GIS cloud computing may also provide prop up technology infrastructure (e.g., leverage of virtualized sophisticated hardware and software resources), plummeting support and continuance (e.g., complimenting for highly skilled in-house staff and IT support), reducing realization cost, location independent resource pooling, and data conversion and presentation (e.g., transformation and importing from one format into a new database). 
3.12. National GIS Policy. Priority setting is one of the major roles of vector-borne and/or infectious disease services decision-makers. The information acquired through the human health information system should be apposite to facilitate decision makers to necessitate the accomplishment of control programmes, enhancing a wide usage of GISbased decision support at all levels: local, regional, and national. There is a need for a single-window organisation for generating/maintaining the map/image and GIS datasets as a common GIS-ready data for the nation and also for developing the GIS applications for ministries/departments.

\section{Future Outlook and Conclusion}

Studies using remote sensing and GIS technologies with applications targeted to VL control programme in India have shown restricted utility for both risk mapping and prediction for the micro to macro scale. The majority of the above applications focus upon secluded identification of sand fly habitats and the prediction of mosquito numbers. Nevertheless, several important issues were addressed and entail further study to refine the tools and broaden their applicability. It is reported that the transmission and propagation of VL and $P$. argentipes distribution depend on climatic, ecological, epidemiological, and socioeconomic determinants that are idiosyncratic to locality, and hence large heterogeneities occur at different scales [24, 42-44]. An important intend of RS and GIS applications for VL transmission is to offer information on the distribution of infection risk and to guide disease interventions. In this connection it is important to note that infection rates in human that act as reservoirs for VL transmission (e.g., post-kala-azar dermal leishmaniasis, PKDL) are significantly higher, as observed in the four main states (e.g., Bihar, Jharkhand, West Bengal, and Uttar Pradesh) of India [6]. Previous study has shown the conspicuous increase of visceral leishmaniasis cases in India, especially in Bihar $[45,46]$. One of the factors for increasing trend of the disease could be due to the increase in reporting of kala-azar cases at public health centers (PHCs) due to massive kala-azar awareness programme undertaken by health agencies and Government of India. However, the relevance of these findings for VL control has been highlighted in this paper, and the use of GIS and RS can cooperate a vital role for mapping and predicting probable areas for VL risk by compiling all these data into a single platform.

The substantial progress made in the control of VL in India has been highlighted in several recent publications [4750]. However, there is a great need to rigorously implement control interventions in those areas where the disease continues to be endemic, as documented by the latest available data of VL on a national scale $[45,46,51,52]$. In fact, north Bihar (India) that covers 31 districts along the Ganges River is characterized by high population densities, suitable climate, and large areas that are favourable for proliferation of $P$. argentipes breeding. It has been conferred that the mean LST, relative humidity, rainfall, surface dampness, settlement areas, low vegetation density zone, moist fallow land could introduce abundance of vector and be endemic for the disease [12-14, 22, 25, 27]. Application of GIS and RS technologies has proven most useful for assessment and monitoring of ecological transformation and hence holds promise to make further progress in the control of VL in India.

In the previous studies, it was considered that much more validation of the relationship between kala-azar admissions and environmental variables was required to check its robustness in space and time. The mapping of kala-azar seasonality is an important goal because climatic variables in an area also can strongly influence the availability of breeding sites for sand fly [51, 53, 54], and national kalaazar control programmes lack detailed disease-risk maps to guide intervention. Multitemporal facility of satellite sensor was important because it assisted the move to seasonal analysis, which, in turn, enabled the investigation of more subtle variation in environmental variables, and thus sand fly habitat suitability. However, operational application of the optical remote sensing technique $(0.4 \mu \mathrm{m}-0.7 \mu \mathrm{m}$ spectral regions) was hindered because investigators were not enabling to discriminate the land cover features in the rainy season due to heavy downpour. A significant advantage of using Synthetic Aperture Radar (SAR) was that data collection was independent of cloud coverage. A recent alternative approach, however, has demonstrated that landbased radar may be capable of predicting habitat flooding status $[55,56]$. The information derived from the satellite data may be used to guide surveys during the rainy season and aids to delineate the suitable breeding areas of sand fly.

That the suite of ecological factors that influence kala-azar transmission concentrated in a particular continental areas and through time is astounding. The number and interaction of dependent factors result in a formidable complexity. The instantaneous response of researchers will be to move to area-specific monitoring of disease risk with the need to validate predictions over wider areas at increasingly higher spatial resolutions. Notwithstanding the desirability of these predictions to direct the relevant epidemiological data to direct kala-azar control, test predictions are often scarce and initial maps should therefore be used with care. Such studies are promising retrospectively with current satellitesensor systems, where existing sand fly population records are accessible but will become increasingly realistic with data from the next generation of satellite sensors.

Currently, India has successfully launched a satellite (Radar Imaging Satellite (RISAT)-1) that connoisseurs speak will spectacularly boost the country's knack to view detailed images of the earth. RISAT 1 springs microwave signals off the earth, which indicate an annual monsoon season during which heavy cloud cover can blight the usefulness of optical satellite imagery. Many new satellitesensor systems are scheduled for launch to concur with the millennium (http://www.lyngsat.com/launches/), and while most represent simple refinements of existing satellite-sensor series. Alternatively, DigitalGlobe's WorldView-2 Satellite provides $0.5 \mathrm{~m}$ Panchromatic (B\&W) mono and stereo satellite image data and provides highly detailed imagery for precise map creation, change detection, and in-depth image 
analysis. WorldView-2 Satellite is offering incredible accuracy, agility, capacity, and spectral diversity and will allow DigitalGlobe to substantially expand its imagery product offerings to both commercial and government customers (http://www.satimagingcorp.com/media/pdf/WorldView-2_ datasheet.pdf). On the other hand, GeoEye- 2 is in a phased development process for an advanced, third-generation satellite capable of discerning objects on the earth's surface as small as 0.25 meter (9.75 inch) in size (http:// www.satimagingcorp.com/satellite-sensors/geoeye-

2.html). In anticipation of these advances, it is prudent for epidemiologists to begin collecting georeferenced field data (using hand-held global positioning systems) as a regular addition to existing projects.

The multiplicity of satellite and sensors offer data relevant to spatial, spectral, and temporal scales. Indeed, using a wide range of remotely sensed imagery to help understand the distribution of sand fly and vector-borne diseases, research has advanced significantly from suitable peri domestic breeding identification at high spatial resolution; to work that has contingent habitat suitability for adult sand flies. Furthermore, image processing and GIS software are available that computerize many image processing tasks and suitable analysis. Finally, and perhaps most importantly, satellite-sensor data have become more widely and freely available (http://www.landcover.org/; http://www.bhuvan.nrsc.gov.in/) especially to research workers in developing countries where the VL confront is the greatest. Geospatial technology can provide information important in predicting the spatial and temporal distribution of VL, thereby allowing presented resources for research and control to be better directed. Research involving remotely sensed variables to sand fly habitat is an indispensable basis for future "disease forecasting" for an early warning system.

\section{Conflict of Interests}

The authors declare that there is no conflict of interests.

\section{Authors' Contributions}

G. S. Bhunia and S. Kesari have equal contribution.

\section{Acknowledgments}

The authors are very much grateful to the State Health Society, Bihar, for freely providing the disease incidence report. They are very much thankful to the Indian Council of Medical Research (ICMR), New Delhi, for their financial support under the senior research fellowship grant.

\section{References}

[1] C. P. Thakur, "Treatment of kala-azar in India," National Medical Journal of India, vol. 5, no. 5, pp. 203-205, 1992.

[2] S. Sundar and H. W. Murray, "Gamma interferon in the treatment of kala-azar and other forms of Leishmaniasis," The Journal of the Association of Physicians of India, vol. 43, no. 5, pp. 348-350, 1995.
[3] S. L. Croft, L. Vivas, and S. Brooker, "Recent advances in research and control of malaria, leishmaniasis, trypanosomiasis and schistosomiasis," Eastern Mediterranean Health Journal, vol. 9, no. 4, pp. 518-533, 2003.

[4] P. Desjuex, "Leishmaniasis: current situation and new perspectives," Comparative Immunology, Microbiology and Infectious Diseases, vol. 27, no. 5, pp. 305-318, 2004.

[5] P. J. Hotez, J. H. F. Remme, P. Buss, G. George, C. Morel, and J. G. Breman, "Combating tropical infectious diseases: report of the disease control priorities in developing countries project," Clinical Infectious Diseases, vol. 38, no. 6, pp. 871-878, 2004.

[6] D. Bora, "Epidemiology of visceral leishmaniasis in India," National Medical Journal of India, vol. 12, no. 2, pp. 62-68, 1999.

[7] J. R. Arias, P. S. Monteiro, and F. Zicker, "The reemergence of visceral leishmaniasis in Brazil," Emerging Infectious Diseases, vol. 2, no. 2, pp. 145-146, 1996.

[8] T. K. Jha, "Drug unresponsiveness \& combination therapy for kala-azar," Indian Journal of Medical Research, vol. 123, no. 3, pp. 389-398, 2006.

[9] F. Laguna, "Treatment of leishmaniasis in HIV-positive patients," Annals of Tropical Medicine and Parasitology, vol. 97, supplement 1, pp. S135-S142, 2003.

[10] R. K. Singh, H. P. Pandey, and S. Sundar, "Visceral leishmaniasis (kala-azar): challenges ahead," Indian Journal of Medical Research, vol. 123, no. 3, pp. 331-344, 2006.

[11] P. Das, S. Samuels, P. Desjeux et al., "Annual incidence of visceral leishmaniasis in an endemic area of Bihar, India," Tropical Medicine and International Health, vol. 15, supplement 2, pp. 4-11, 2010.

[12] G. S. Bhunia, N. Chatterjee, V. Kumar, R. Mandal, P. Das, and S. Kesari, "Remote sensing and GIS: tools for the prediction of epidemic for the intervention measure," in Proceedings of the 14th Annual International Conference and Exhibition on Geospatial Information technology and Application, Gurgaon, India, February 2012, India Geospatial forum (PN-31).

[13] G. S. Bhunia, S. Kesari, A. Jeyaram, V. Kumar, and P. Das, "Influence of topography on the endemicity of kala-azar: a study based on remote sensing and geographical information system," Geospatial Health, vol. 4, no. 2, pp. 155-165, 2010.

[14] G. S. Bhunia, V. Kumar, A. J. Kumar, P. Das, and S. Kesari, "The use of remote sensing in the identification of the ecoenvironmental factors associated with the risk of human visceral leishmaniasis (kala-azar) on the Gangetic plain, in NorthEastern India," Annals of Tropical Medicine and Parasitology, vol. 104, no. 1, pp. 35-53, 2010.

[15] S. Kesari, G. S. Bhunia, V. Kumar, A. Jeyaram, A. Ranjan, and P. Das, "A comparative evaluation of ground survey and space technology of endemic and non-endemic region of Visceral Leishmaniasis (kala-azar) in India," Memórias do Instituto Oswaldo Cruz, vol. 106, no. 5, pp. 515-523, 2011.

[16] S. Sudhakar, T. Srinivas, A. Palit, S. K. Kar, and S. K. Battacharya, "Mapping of risk prone areas of kala-azar (Visceral leishmaniasis) in parts of Bihar state, India: an RS and GIS approach," Journal of Vector Borne Diseases, vol. 43, no. 3, pp. 115-122, 2006.

[17] N. R. Bergquist, "Schistosomiasis: from risk assessment to control," Trends in Parasitology, vol. 18, no. 7, pp. 309-314, 2002.

[18] S. Brooker, M. Beasley, M. Ndinaromtan et al., "Use of remote sensing and a geographical information system in a national 
helminth control programme in Chad," Bulletin of the World Health Organization, vol. 80, no. 10, pp. 783-789, 2002.

[19] S. I. Hay, "An overview of remote sensing and geodesy for epidemiology and public health application," Advances in Parasitology, vol. 47, pp. 1-35, 2000.

[20] L. R. Leonardo, P. T. Rivera, B. A. Crisostomo et al., "A study of the environmental determinants of malaria and schistosomiasis in the Philippines using remote sensing and geographic information systems," Parassitologia, vol. 47, no. 1, pp. 105-114, 2005.

[21] G. J. Yang and X. N. Zhou, "Application of GIS/RS on vectorborne diseases control," Chinese Journal of Parasitic Disease Control, vol. 14, pp. 64-66, 2001.

[22] G. S. Bhunia, S. Kesari, N. Chatterjee, V. Kumar, and P. Das, "Localization of kala-azar in the endemic region of Bihar, India based on land use/land cover assessment at different scales," Geospatial Health, vol. 6, no. 2, pp. 177-193, 2012.

[23] P. Nieto, J. B. Malone, and M. E. Bavia, "Ecological niche modeling for visceral leishmaniasis in the state of Bahia, Brazil, using genetic algorithm for rule-set prediction and growing degree day-water budget analysis," Geospatial Health, vol. 1, no. 1, pp. 115-126, 2006.

[24] R. A. Thompson, J. W. de Oliveira Lima, J. H. Maguire, D. H. Braud, and D. T. Scholl, "Climatic and demographic determinants of American visceral leishmaniasis in northeastern Brazil using remote sensing technology for environmental categorization of rain and region influences on leishmaniasis," American Journal of Tropical Medicine and Hygiene, vol. 67, no. 6, pp. 648-655, 2002.

[25] G. S. Bhunia, S. Kesari, N. Chatterjee et al., "Incidence of visceral leishmaniasis in the Vaishali district of Bihar, India: spatial patterns and role of inland water bodies," Geospat Health, vol. 5, no. 2, pp. 205-215, 2011.

[26] P. Malaviya, A. Picado, S. P. Singh et al., "Visceral leishmaniasis in Muzaffarpur district, Bihar, India from 1990 to 2008," PLoS ONE, vol. 6, no. 3, Article ID e14751, 2011.

[27] G. S. Bhunia, N. Chatterjee, V. Kumar et al., "Delimitation of kala-azar risk areas in the district of Vaishali in Bihar (India) using a geo-environmental approach," Memórias do Instituto Oswaldo Cruz, vol. 107, no. 5, pp. 609-620, 2012.

[28] A. Jeyaram, S. Kesari, A. Bajpai, G. S. Bhunia, and Y. V. N. Krishna Murthy, "Risk zone modelling and early warning system for visceral leishmaniasis (kala-azar) disease in Bihar, India using remote sensing and GIS," in Proceedings of the 22nd Congress of the International Society for Photogrammetry and Remote Sensing, Melbourne Convection and Exhibition Centre, Melbourne, Australia, August 2012.

[29] S. K. Paul, A. Jeyaram, and V. Jayaraman, "Application of remote sensing and GIS in identifying and mapping sandfly distribution in endemic and non-endemic kala-azar foci in Bihar and Jharkhand," in Proceedings of the 57th AIAA International Astronautical Congress (IAC'06), pp. 2372-2387, October 2006, IAC-06-B1.P.1.17.

[30] M. H. Craig, R. W. Snow, and D. Le Sueur, "A climate-based distribution model of malaria transmission in sub-Saharan Africa," Parasitology Today, vol. 15, no. 3, pp. 105-111, 1999.

[31] J. A. Omumbo, S. I. Hay, C. A. Guerra, and R. W. Snow, “The relationship between the Plasmodium falciparum parasite ratio in childhood and climate estimates of malaria transmission in Kenya," Malaria Journal, vol. 3, article 17, 2004.
[32] B. R. W. Snow, M. H. Craig, U. Deichmann, and D. Le Sueur, "A preliminary continental risk map for malaria mortality among African children," Parasitology Today, vol. 15, no. 3, pp. 99-104, 1999.

[33] J. R. Everett, R. J. Staskowski, and C. Jengo, "Remote sensing and GIS enable future exploration success," World Oil, vol. 223, no. 11, pp. 59-65, 2002.

[34] P. Geerders, "Remote sensing—challenges for ACP countries," 2005, http://knowledge.cta.int/en/Dossiers/S-T-Issues-in-Perspective/Remote-sensing-and-GIS/Articles/Remote-SensingChallenges-for-ACP-countries.

[35] A. Ghosh, Remote Sensing Data Policies, Geospatial World (Geospatial Communication Network), 2010, http://geospatialworld.net/index.php?option=comcontent\&view=article $\&$ id $=20307 \&$ Itemid $=1304$.

[36] S. Gao, D. Mioc, F. Anton, X. Yi, and D. J. Coleman, "Online GIS services for mapping and sharing disease information," International Journal of Health Geographics, vol. 7, article 8, 2008.

[37] S. Todd, G. Brubaker, S. Chand et al., "Human resourcesgeographical information systems data development and systems implementation for the christian social services commission of tanzania: final report," HR-GIS Data Development and Systems Implementation for the CSSC of Tanzania, United State Agency International Development (USAID), 2009.

[38] T. Toutin and P. Cheng, "QuickBird-a milestone for highresolution mapping," Earth Observation Magazine, vol. 11, pp. 14-18, 2002.

[39] M. A. Bhat, R. M. Shah, and B. Ahmed, "Cloud computing: a solution to geographical information systems (GIS)," International Journal on Computer Science and Engineering, vol. 3, no. 2, pp. 594-600, 2011.

[40] L. J. Zhang and Q. Zhou, "CCOA: cloud computing open architecture," in Proceedings of the IEEE International Conference on Web Services (ICWS'09), pp. 607-616, Los Angeles, Calif, USA, July 2009.

[41] I. Foster, Y. Zhao, I. Raicu, and S. Lu, "Cloud computing and grid computing 360-degree compared," in Proceedings of the Grid Computing Environments Workshop (GCE'08), pp. 1-10, Austin, Tex, USA, November 2008.

[42] M. C. Thomson, D. A. Elnaiem, R. W. Ashford, and S. J. Connor, "Towards a kala azar risk map for Sudan: mapping the potential distribution of Phlebotomus orientalis using digital data of environmental variables," Tropical Medicine and International Health, vol. 4, no. 2, pp. 105-113, 1999.

[43] D. E. A. Elnaiem, J. Schorscher, A. Bendall et al., "Risk mapping of visceral leishmaniasis: the role of local variation in rainfall and altitude on the presence and incidence of kala-azar in Eastern Sudan," American Journal of Tropical Medicine and Hygiene, vol. 68, no. 1, pp. 10-17, 2003.

[44] B. P. Sharma, N. M. Maskay, S. R. Adhikari et al., "Socioeconomic determinants of kala-azar in Nepal," Journal of Nepal Health Research Council, vol. 2, no. 1, pp. 35-42, 2004.

[45] B. Ostyn, K. Gidwani, B. Khanal et al., "Incidence of symptomatic and asymptomatic Leishmania donovani infections in high-endemic foci in India and Nepal: a prospective study," PLOS Neglected Tropical Diseases, vol. 5, no. 10, Article ID e1284, 2011.

[46] V. P. Singh, A. Ranjan, R. K. Topno et al., "Short report: estimation of under-reporting of visceral leishmaniasis cases in Bihar, India," American Journal of Tropical Medicine and Hygiene, vol. 82, no. 1, pp. 9-11, 2010. 
[47] R. P. Goswami, B. Bairagi, and P. K. Kundu, "K39 strip test-easy, reliable and cost-effective field diagnosis for visceral leishmaniasis in India," Journal of Association of Physicians of India, vol. 51, pp. 759-761, 2003.

[48] P. J. Guerin, P. Olliaro, S. Sundar et al., "Visceral leishmaniasis: current status of control, diagnosis, and treatment, and a proposed research and development agenda," The Lancet Infectious Diseases, vol. 2, no. 8, pp. 494-501, 2002.

[49] D. Mondal, S. P. Singh, N. Kumar et al., "Visceral leishmaniasis elimination programme in India, Bangladesh, and Nepal: reshaping the case finding/case management strategy," PLoS Neglected Tropical Diseases, vol. 3, no. 1, article e355, 2009.

[50] A. Stauch, R. R. Sarkar, A. Picado et al., "Visceral leishmaniasis in the Indian subcontinent: modelling epidemiology and control," PLOS Neglected Tropical Diseases, vol. 5, no. 11, Article ID e1405, 2011.

[51] N. S. Singh and D. P. Singh, "Seasonal occurrence of phlebotominae sand flies (phlebotominae: Diptera) and it's correlation with kala-azar In eastern Uttar Pradesh, India," Southeast Asian Journal of Tropical Medicine and Public Health, vol. 40, no. 3, pp. 458-462, 2009.

[52] S. P. Singh, D. C. S. Reddy, M. Rai, and S. Sundar, "Serious underreporting of visceral leishmaniasis through passive case reporting in Bihar, India," Tropical Medicine and International Health, vol. 11, no. 6, pp. 899-905, 2006.

[53] A. Picado, M. L. Das, V. Kumar et al., "Phlebotomus argentipes seasonal patterns in India and Nepal," Journal of Medical Entomology, vol. 47, no. 2, pp. 283-286, 2010.

[54] N. Bacaër and S. Guernaoui, "The epidemic threshold of vector-borne diseases with seasonality: the case of cutaneous leishmaniasis in Chichaoua, Morocco," Journal of Mathematical Biology, vol. 53, no. 3, pp. 421-436, 2006.

[55] S. Kaya, J. Sokol, and T. J. Pultz, "Monitoring environmental indicators of vector-borne disease from space: a new opportunity for RADARSAT-2," Canadian Journal of Remote Sensing, vol. 30, no. 3, pp. 560-565, 2004.

[56] S. G. Ross, M. C. Thomson, T. Pultz, C. M. Mbogo, J. L. Regens, and C. Swalm, "On the use of RADARSAT-1 for monitoring malaria risk in Kenya," in Proceedings of the Third International Symposium on Retrieval of Bio- and Geophysical Parameters From SAR Data For Land Applications, 11-14 September, 2001 in Sheffield, UK, A. Wilson, Ed., ESA Publications Division, Noordwijk, The Netherlands, 2002, Scientific coordination by S. Quegan, ESA SP-475. 


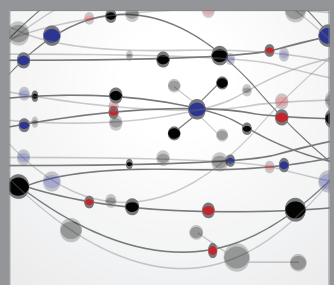

The Scientific World Journal
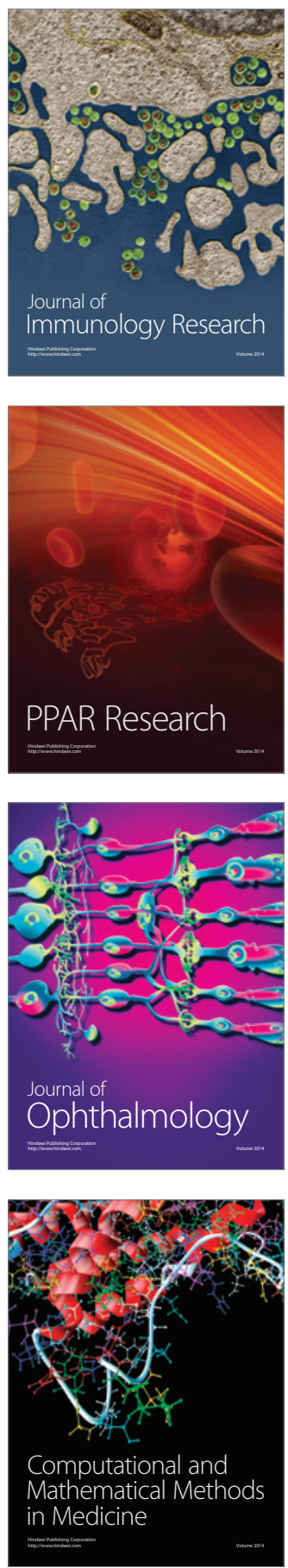

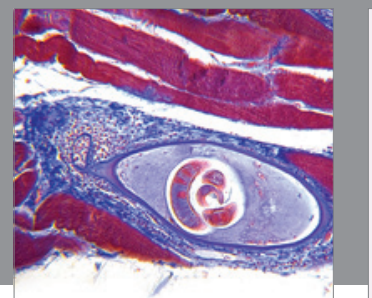

Gastroenterology

Research and Practice
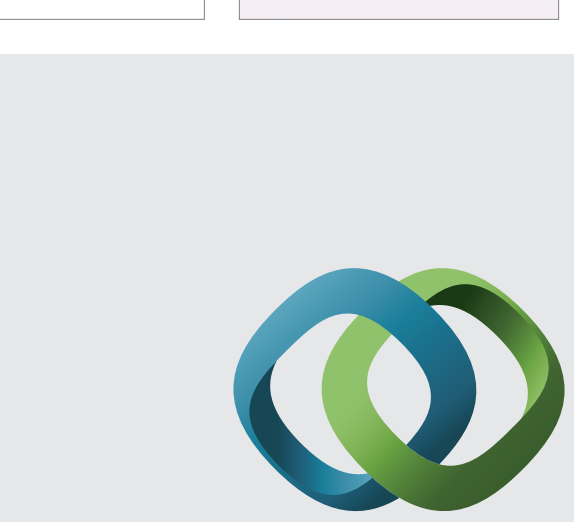

\section{Hindawi}

Submit your manuscripts at

http://www.hindawi.com
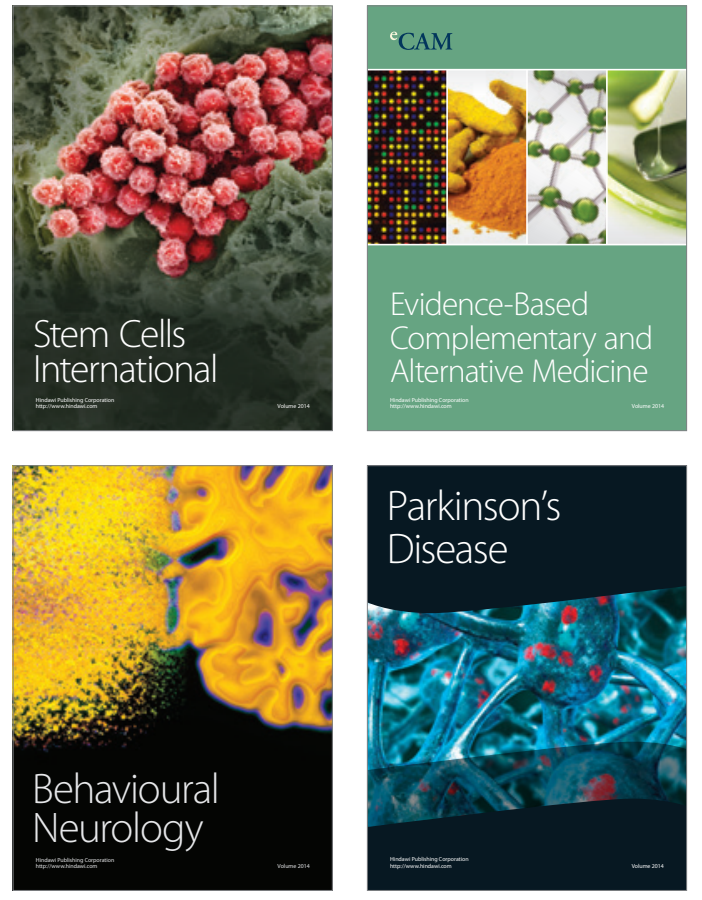
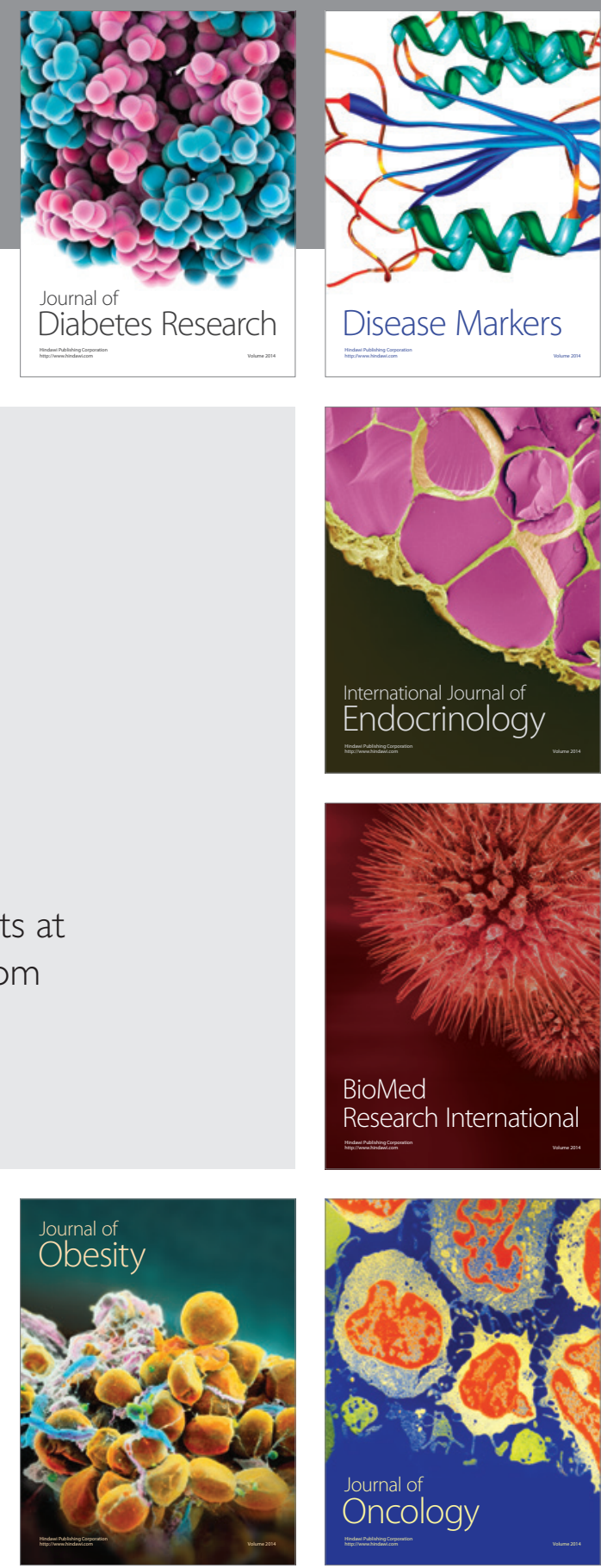

Disease Markers
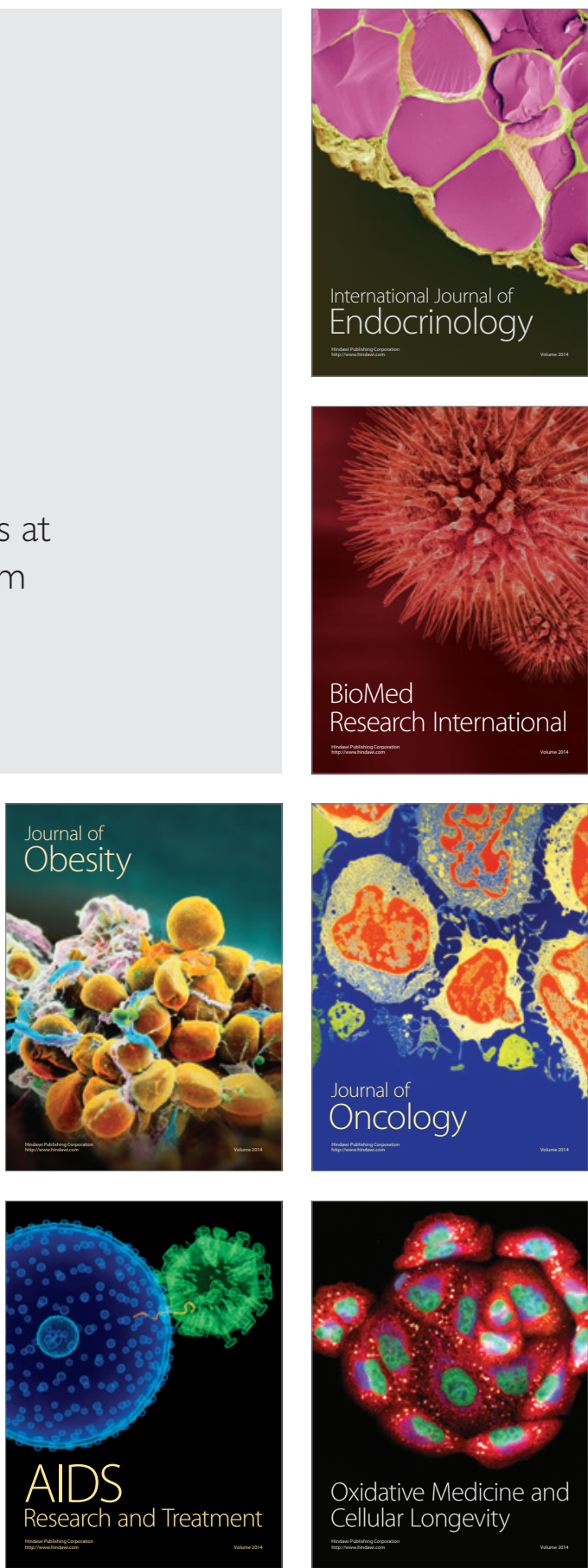